\title{
FATORES DE ATRATIVIDADE DO CLUSTER VAREJISTA MERCADO VER-O-PESO
}

Bárbara Fernandes ${ }^{1}$

Sérgio Castro Gomes ${ }^{2}$

Cynthia Meireles Martins ${ }^{3}$

Rosinele De Oliveira ${ }^{4}$

\footnotetext{
${ }^{1}$ UNIVERSIDADE DA AMAZÔNIA -UNAMA

${ }^{2}$ Professor Doutor do PPGA / Universidade da Amazonia / UNAMA

${ }^{3}$ Professora Doutora do PPGA / Universidade da Amazonia / UNAMA

${ }^{4}$ Doutoranda em Administração do PPGA da UNAMA / Universidade da Amazonia / UNAMA
} 


\section{FATORES DE ATRATIVIDADE DO CLUSTER VAREJISTA MERCADO VER-O-PESO}

Resumo: Antes de falar acerca do objetivo que moveu essa pesquisa, os autores precisam retratar um ponto da relevância do Mercado Ver-o-Peso como espaço importante de comercialização de produtos regionais, são eles: frutas, ervas, condimentos, plantas medicinais, pescados, além de pratos típicos da culinária paraense. Aproximadamente cinco mil pessoas trabalham em 12 setores do espaço regional de $30 \mathrm{mil} \mathrm{m}^{2}$, em média mais de 40 mil pessoas circulam por dia no mercado, a pesquisa tem como objetivo identificar quais são os fatores responsáveis pela atratividade do cluster varejista Mercado Ver-o-Peso sob a percepção dos consumidores. Desenvolveu-se um estudo descritivo de natureza quantitativa, onde aplicou-se um questionário estruturado com 24 variáveis observáveis, representadas por: produtos, preços, lojas, atendimento, localização e condições de compra. Com uma amostra não probabilística, foram entrevistados 159 consumidores. O estudo aponta que a variável localização é considerada o fator mais atrativo para os consumidores frequentadores do Mercado Ver-o-Peso.

Palavras-chave: Cluster varejista. Mercado Ver-o-Peso. Atratividade.

\section{Introdução}

Em grandes cidades têm sido comum a concentração de lojas varejistas que comercializam o mesmo tipo de produto ou produtos complementares, como é o caso da Rua 25 de março no segmento de armarinho e bijuterias, confecções na Rua Oriente, móveis na Rua Teodoro Sampaio, joias na Rua Barão de Paranapiacaba mais conhecida como rua do ouro, produtos naturais na Rua Santa Rosa mais conhecida como zona cerealista, material hospitalar na Rua Borges Lagoa, automóveis na Avenida Marechal Tito, todas situadas na cidade de São Paulo (SILVA, 2016).

No entendimento de Gaspar et al. (2015), nas pesquisas de autores como Porter (1990); Zaccarelli et al. (2008); Teller (2008) e Amato Neto (2009) têm sido identificadas vantagens competitivas nas concentrações geográficas de empresas. Esses autores evidenciam o fato de um grupo de empresas se reunirem em um mesmo local (aglomerados), com o objetivo de transacionarem produtos semelhantes, para competir com outras empresas que não pertencem ao agrupamento, denominando-se tal contexto como cluster (GASPAR et al. 2015).

Estudos destacam a teoria de varejo afirmando que essas concentrações geográficas de empresas podem ser caracterizadas como clusters varejistas (ROGERS, 1965; INGENE, 1984; ARENTZE; OPPEWAL; TIMMERMANS, 2005; PARENTE, 2009; SOUZA, 2013; TELLES et al., 2013; AGUIAR; PEREIRA; DONAIRE, 2014, GASPAR et al. 2015; SOUZA et al. 2014; SIQUEIRA; TELLES, 2015; SILVA, 2016).

Diante disso, Siqueira e Telles (2015, p. 31) entendem que "os clusters apresentam uma característica de especial interesse para a área de estratégia, que é a capacidade elevada de competir, de propiciar e sustentar o desenvolvimento de regiões". Essa capacidade elevada de competir ocorre nos clusters industriais, de serviços e de varejo. Na atividade varejista em geral, a literatura aborda a existência de relações entre as atratividades que os clientes têm da loja com o seu sucesso econômico, bem como sua escolha como o local para fazer compras, além da lealdade que muitos consumidores nutrem a uma empresa.

Nesse sentido, Silva et al. (2014) afirmam que, especificamente em relação à abordagem do conceito de atratividade de lojas varejistas em clusters, percebe-se poucos estudos voltados a

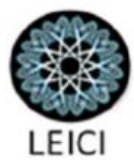


essa temática. É no intuito de enfatizar esse conceito que a presente pesquisa pretende identificar e avaliar a importância dos fatores formadores da atratividade nos clusters varejistas, utilizando a proposição e o teste empírico de um modelo elaborado com base na literatura de marketing de varejo e serviços, e na literatura sobre a atratividade em clusters varejistas, baseada nas pesquisas de Silva et al. (2014).

O Mercado Ver-o-Peso é considerado um cartão postal da Amazônia brasileira, é também conhecido como a maior feira livre a céu aberto da América Latina e frequentado por consumidores nacionais e internacionais. Está localizado às margens do Rio Guamá, pertencente à Baía do Guajará. É também onde se concentram os principais pontos turísticos de Belém, como o já citado Mercado Ver-o-Peso, Complexo Feliz Lusitânia e Estação das Docas. Assim, este estudo tem como objetivo identificar quais são os fatores promotores e detratores que influenciam na atratividade do Mercado Ver-o-Peso segundo a percepção dos consumidores.

\section{Referencial Teórico}

\subsection{Atratividade}

No entendimento de Martineu (1958, p. 12), a atratividade de uma loja pode ser identificada a partir "do modo como a loja é definida na mente do consumidor e, em parte, por suas qualidades funcionais, por atributos emocionais e psicológicos". Berry (1969) vai além, quando indica que a atratividade de uma loja é influenciada por inúmeros fatores e os destaca: preço, qualidade, variedade e atualidade das mercadorias, atendimento do pessoal de vendas, promoção, serviços oferecidos a clientes, propaganda, atmosfera e ambiente da loja, conveniência quanto a estacionamento e horário de atendimento, bem como a reputação em situações eficientes de pós-venda.

Jolson e Spath (1973) avançam quando identificam uma hierarquia no nível de importância entre atributos que os consumidores consideram na escolha de aquisição de produtos e destacam que o preço, seguido de especialização da loja, qualidade das mercadorias, serviço de venda, localização, variedade do sortimento, política de troca e garantia, hábitos e rotinas, legitimidade das vendas e outros como: entrega, estacionamento, horário de funcionamento.

Por outro lado, Dickson e Albaum (1977) usaram métrica com 29 variáveis para mensurar a atratividade do varejo; esses autores aglutinaram os 29 itens em dois fatores: ambiente de compra e promoção - preço de produtos. O fator ambiente de compra e promoção envolve a limpeza, organização e atmosfera da loja. Quanto ao preço, envolve todos os itens relacionados a preço e a relação preço/valor.

Na visão de Costa e Almeida (2008), as compras são influenciadas pela maneira com que o consumidor aponta a importância diferenciada dos atributos das lojas, como: proximidade, disponibilidade de produtos, velocidade, certeza de encontrar o produto desejado, diversidade, qualidade e atualidade de produtos, nível de preço, pós-venda e design da loja.

Estudo de Burt e Carralero-Encinas (2000), por meio de métrica, pesquisou a percepção dos consumidores sobre os atributos e atratividade de uma loja e identificou: serviços ao cliente que incluem presteza e conhecimento técnico dos funcionários, política de devolução e nível de serviço. Ademais, a reputação da loja e essa, inclui a imagem de confiança, justiça e credibilidade, portanto, esses são caracterizados como atributos intangíveis.
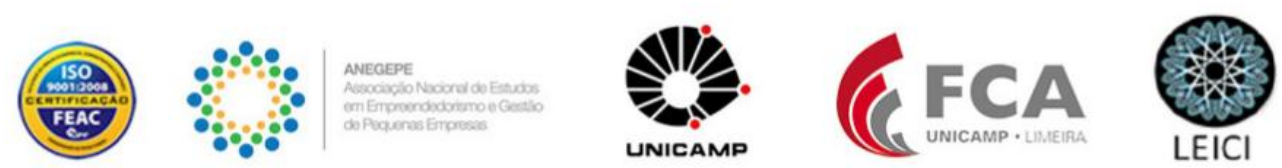
Pesquisa efetuada por Baker, Parsurama e Grewal (2002), quanto à percepção do consumidor na decisão de compra, concluiu que a aparência dos empregados e o design da loja possuem relação positiva com a intenção de compra.

Parente (2009), por sua vez, entende que os consumidores avaliam produtos e estabelecimentos por critérios denominados de atributos, inobstante o conjunto de atributos é determinado de acordo com o tipo de varejo, é possível classificá-los em relação as seis variáveis do mix varejista (6 P's): produtos, preços, apresentação, promoção, pessoal, ponto / localização. Como segue:

P-PRODUTO: Variedade, Qualidade, Exclusividade.

P-APRESENTAÇÃO: Layout, Decoração/ Atmosfera, Comunicação visual e Conforto.

P-PREÇO: Preço, Benefício / Custos, Prazo e Forma de Pagamento.

P-PROMOÇÃO: Propaganda, Promoção no Ponto de Venda, Programa de Fidelização.

P-PESSOAL: Atendimento, Interesse e Cortesia, Qualificação.

P-PONTO E LOCALIZAÇÃO: Proximidade, Facilidade de Acesso, Complementariedade com outras lojas.

As variáveis identificadas nesse estudo como 6P's se acentuam quando a entidade empreendedora atua em aglomerado empresarial, pois esses aglomerados são formados por diferentes lojas, o que acaba atraindo os consumidores e até mesmo novos empreendedores, gerando o que Silva et al. (2014) chamam de círculo virtuoso de desenvolvimento comercial. Tendo em vista a pesquisa de Telles et al. (2013) realizada no centro comercial de São Paulo em dois aglomerados do setor varejista, eletroeletrônico e informática, o outro no segmento de acessórios para noivos, na rua Santa Ifigênia e São Caetano, respectivamente, identificaram que o fator preço foi considerado o atributo mais importante na atratividade da Rua Santa Ifigênia; já na rua São Caetano o atributo de destaque foi condições de compra.

\subsection{Cluster Varejista}

As ideias sobre aglomerados de empresas não são novas, diante disto, registra-se Alfred Marshall com a tradicional obra Principles of Economics, publicada em 1920, onde o autor destaca os ganhos relacionados à atuação de empresas em um mesmo espaço geográfico e condições físicas, tais como clima e solo, além da aproximação do mercado consumidor.

As embrionárias reflexões despertadas por Marshall possibilitaram discussões sobre a importância da concentração espacial para o desenvolvimento econômico e social (MILANEZ; PUPPIM, 2009), para a geração de emprego (BRITO et al., 2010) e vantagens competitivas (SOUZA; ARICA, 2006). Avançando no tempo identifica-se que antes da década de 1990, os agrupamentos de empresas em determinada região geográfica, normalmente em pequenas cidades, era fato intrigante (ZACCARELLI et al., 2008).

No final da década de 1980, Michel Porter estava no ápice de seu prestígio como pesquisador da teoria de estratégia empresarial e, nesse sentido, realizou pesquisa que deixou de enfatizar aspectos internos das empresas e buscou identificar fatores exógenos que originavam a vantagem competitiva das nações, deixando, assim, de dar enfoque à empresa isolada.

A amostragem de Porter foi em dez países, incluindo mais de cem produtos exportáveis com o objetivo de identificar o que estava associado à vantagem competitiva daquelas nações e daqueles produtos. A pesquisa de Porter gerou o livro intitulado "Vantagem Competitiva das Nações", publicado em 1990, e dentre os resultados é possível destacar que a vantagem competitiva era de cidades e não de nações, pois, as mercadorias eram produzidas por

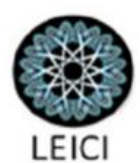


aglomerados empresariais em cidades e daí exportadas para o mundo. Implícito ficou que a vantagem competitiva não era das empresas e sim do agrupamento de empresas o que o autor denominou esse agrupamento de Clusters.

Porter (1990) analisou a competitividade das regiões industriais pelos estímulos recíprocos entre competidores, alimentados por insights significativos que as economias agregadas e interrelacionadas proporcionam por meio da vantagem competitiva da região. Além da competição estimulada, o autor se refere também às possibilidades de cadeias horizontais associadas pela complementação de produtos ou serviços entre atores do aglomerado.

Porter (1990) definiu cluster como sendo concentrações geográficas de empresas relacionadas, fornecedores especializados, entidades prestadoras de serviços e outras entidades voltadas à atuação em setores correlatos, além de outras instituições específicas, tais como as universidades, associações comerciais, agências de crédito entre outras, que competem, mas também cooperam entre si, daí a origem do termo contemporâneo denominado de coopetição. Pesquisas clássicas como as de Porter $(1985,1990)$, Shimitz (1992), como também as mais recentes efetuadas por Zaccarelli et al., (2008), Siqueira, Gerth e Boa Ventura (2011), identificaram vantagem competitiva oriunda de concentrações de empresas em uma determinada região. Segundo esses autores, a reunião de empresas em aglomerações é uma estratégia eficaz para torná-las competitivas. Na visão de Zaccarelli et al., (2008), cluster deve ser percebido como "sistema", cujas partes mais relevantes são empresas interagindo entre si, de forma peculiar e específica, e o resultado dessas interações é uma notável capacidade de competir.

\subsection{O Mercado Ver-o-Peso}

Considerado a maior feira livre da América Latina, sua história tem a peculiaridade do mercado ter surgido no século XVII como entreposto comercial e fiscal em área adjacente ao igarapé do Piri. Seu abastecimento é realizado por produtores residentes nas inúmeras ilhas que circunvizinham a capital paraense. Neste mercado os produtos eram pesados e os preços taxados, tal fato, lhe atribuiu o nome de "Casa de Haver o Peso" (SECRETARIA MUNICIPAL DE ECONOMIA-SECON, 2016).

A natural evolução fez com que o igarapé do Piri sofresse aterramento, e assim ocorreu sua expansão, surgiu as Docas do Ver-o- Peso, porto para as embarcações regionais, caracterizouse também como expressivo entreposto de venda de peixes, fatos que impulsionaram a importância econômica para a região norte do Brasil (SECON, 2016).

Hoje o Departamento Intersindical de Estatística e Estudos Socioeconômicos (DIEESE), informa que as pequenas atividades econômicas do Mercado Ver-o-Peso injetam na economia paraense em torno de um milhão por dia, onde aproximadamente entre cinco mil micro empreendedores- MPE e micro empreendedores individual -MEI trabalham em 12 setores do espaço regional de $30 \mathrm{mil} \mathrm{m}^{2}$, cuja circulação média de potenciais compradores gira em torno de 40 mil pessoas/dia (SECON, 2016).

Entre os principais produtos vendidos na feira pelos pequenos empreendedores, destaca-se o açaí, produtos hortifrutigranjeiros, o pescado, extensa e peculiar praça de alimentação a qual privilegia os produtos exclusivamente regionais, tais como o peixe frito adicionado ao açaí. Evidencia-se a relevância do espaço geográfico quando o DIEESE informa que são vendidas no complexo, cerca de 30 toneladas de açaí por ano, 30 toneladas de hortaliças por mês e até 15 toneladas de pescado por dia.

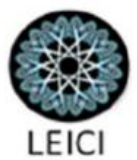


A peculiar paisagem do Mercado Ver-o-Peso não é apenas apreciável, também comporta um mundo de práticas tradicionais relacionadas a dança, pesca e a extração de produtos da floresta amazônica. Este aspecto garante a importância do Mercado Ver-o-Peso pois, situado às margens do rio Guajará, criou-se uma rede de comercialização que faz conexão com a metrópole e às inúmeras ilhas e localidades do entorno, cujo o abastecimento cotidiano de produtos frescos como o pescado, frutas originalmente amazônicas, como: pupunha, castanha do Pará, cupuaçu, o açaí, etc são consumidos. Destaca-se também a extração e preparo de produtos da mandioca muito utilizado pela culinária local, além da famosa cerâmica marajoara. Isso posto, o mercado é conhecido como um importante centro de abastecimento para a população paraense.

O Setor de Ervas é frequentemente lembrado como tradicional, e possui uma representativa participação e presença na mídia local, quando o assunto é "conhecimento tradicional" (CARVALHO; MENDONÇA; STEINBRENNER 2011). A importância desse conhecimento centenário, passado de pai para filho, é muito respeitado pelos paraenses, até mesmo para os que não acreditam no poder de cura das plantas medicinais. As barracas das ervas é um local muito frequentado, não só pelos nativos, mas pelos turistas que visitam Belém. Estar no Mercado Ver-o-Peso é se deliciar com uma mistura de sabores regionais, tradições culturais e cheiros da Amazônia.

\section{Metodologia}

\subsection{Modelo Analítico}

Como modelo analítico usou-se o conceito de atratividade para explicar o que representa a atratividade e a não atratividade sob a ótica do consumidor. Para atender a essa meta usou-se uma escala de 0 a 10, conforme o modelo de Silva et al. (2014).

As notas atribuídas de 0 a 7 pelos consumidores, dizem respeito aos clientes detratores, ou seja, os que não consideram o Mercado Ver-o-Peso atrativo. Já as notas de 8 a 10 representam os clientes promotores, uma vez que reconhecem o mercado como atrativo.

A Figura 3, relaciona a atratividade de clientes com as variáveis do mix varejista (6 P's) em um aglomerado empresarial. Inicialmente buscou-se identificar os efeitos observáveis junto aos consumidores paraenses que já efetuaram pelo menos uma compra no Mercado do Ver-o-Peso, relativos a cada uma das variáveis independentes admitidas, quais sejam: produtos, preços, lojas, atendimento, localização e condições de compra e o objetivo foi tornar acessível a identificação dos fatores detratores e promotores do aglomerado.

Figura: 03 Modelo Analítico

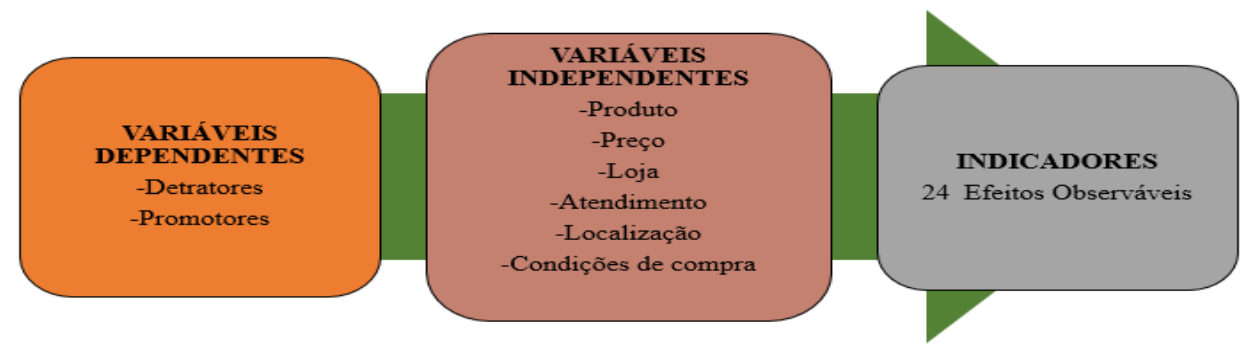

Fonte: Elaborado pelos autores (2017).

Salienta-se que os aspectos evidenciados na Figura 3 foram resumidos em indicadores utilizando-se o modelo de Zaccarelli et al. (2008), o qual apresenta os aspectos fundamentais e

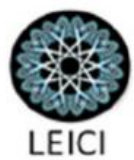


existentes em aglomerados empresariais e que possibilitam o aumento da capacidade competitiva das lojas que lá atuam e comparadas com as que atuam de forma isolada.

\subsection{Tratamento dos Dados}

Os dados foram capturados por meio de uma survey. Utilizou-se questionário estruturado no qual os consumidores atribuíram notas no intervalo de 0 a 10 a cada questão, com a presença e assistência dos pesquisadores, no sentido de esclarecer o que fosse necessário e com isso possibilitou maior número de respostas válidas.

No final do levantamento dos dados, os resultados obtidos foram alvo de inputs em planilha eletrônica Microsoft Excel para posterior transferência para o programa Statistical Package for Social Science (SPSS) com o objetivo de refinar os dados coletados em campo.

A técnica usada para a análise dos dados é denominada de Regressão Logística, pois, esse é método de predição multivariada que é empregado quando as variáveis independentes como: produtos, preços, lojas, atendimento, localização e condição de compras (covariates no SPSS) são utilizadas na explicação de resultados categóricos como a atratividade, variável dependente, a qual é frequentemente dicotômica (atrativa ou não atrativa).

Ademais, o objetivo da regressão logística é avaliar a probabilidade de obtenção de uma das categorias da variável dependente, dado o conjunto de variáveis independentes, permitindo assim, ser considerado um método de predição sempre que existirem inúmeras variáveis independentes. Essa técnica tem como restrição a existência de amostra mínima com cerca de 20 casos por variável independente e com tamanho mínimo nunca inferior a 60 casos (SILVA,2014)

Foram analisadas as premissas da técnica antes descrita por meio das variáveis, aplicando o teste homocedasticidade com o teste Box M e multicolinearidade com a tolerância do VIF. O método de estimação utilizado foi o Enter. Verificou-se o nível de acerto do modelo por meio do critério de chance proporcional, estando em conformidade ao que determina (HAIR, 2009).

\subsection{Hipóteses Relacionadas à Atratividade}

O modelo de hipótese apresentado neste estudo está diretamente relacionado ao termo atratividade do cluster varejista Mercado Ver-o-Peso, aqui se convencionou chamar a variável dependente o constructo atratividade e as variáveis independentes são os fatores produtos, preços, lojas, atendimento, localização e condições de compra. A Figura 4 demonstra os 6 P's do mix varejista do marketing e ao lado estão expressas as seis hipóteses firmadas

Figura 4 - 6 P's e Hipóteses Firmadas

\begin{tabular}{|c|c|}
\hline $\begin{array}{c}\text { 6 P's do Mix Varejista } \\
\text { do Marketing }\end{array}$ & Hipóteses \\
\hline Produtos & $\mathrm{H}_{1}$ \\
\hline Preços & $\mathrm{H}_{2}$ \\
\hline Lojas & $\mathrm{H}_{3}$ \\
\hline Atendimento & $\mathrm{H}_{4}$ \\
\hline Localização & $\mathrm{H}_{5}$ \\
\hline Condições de compras & $\mathrm{H}_{6}$ \\
\hline
\end{tabular}

Fonte: Elaborada pelos autores, 2017. 


\subsubsection{Mix de Produtos}

As preferências e necessidades dos consumidores possuem valor medido por variáveis tais como: intensidade, diversidade e qualidade das mercadorias que os lojistas do varejo disponibilizam ao mercado, isto é, essas variáveis apresentam influência do sortimento de produtos (BERRY, 1969; MANOLIS et al., 1994; BURT, CARRALERO-ENCINAS, 2000; BAKER et al., 2002; BLOEMER; ODEKERKEN-SCHRÖDER, 2002; KOO, 2003; BALTAS, SINHA; BANERJEE, 2001; ORUC, 2005; COSTA; ALMEIDA, 2008).

Para o consumidor é maior a atratividade de um local de compra quando este apresenta variados modelos e marcas de um mesmo produto, assim como esse consumidor percebe a atualidade e a qualidade dos produtos, afora a certeza de que encontra determinado produto com esses atributos em um mesmo local de compra (DE WULF; WATERSCHOOT, 1999; SINHA; BANERJEE, 2001; COSTA; ALMEIDA, 2008). Do mesmo modo, a qualidade das mercadorias influencia na tomada de decisão e constitui importante fator de preferência do consumidor por uma determinada loja (COSTA; ALMEIDA, 2008; BAKER, PARASURAMAN; GREWAL, 2002; ORUC, 2005).

HIPÓTESE 1: A opinião sobre a variedade de produtos ofertados aos consumidores do Mercado Ver-o-Peso, encontra-se associada positivamente com a atratividade.

\subsubsection{Apresentação e Ambiente das Lojas}

A atratividade de um local de compra também possui relação direta com a dimensão ambiente da loja, haja vista que a percepção do consumidor possibilita encontrar produtos bem como o conforto na circulação dos clientes, sendo portanto, influenciada pelo estilo da loja, modernidade e apelo visual das instalações, aparência externa, mobiliário de exposição e visualização dos produtos, assim como também tem influência na atratividade pelo consumidor atributos como limpeza, arrumação e decoração que, no todo, formam a imagem que a loja possui perante o consumidor (BERRY, 1969; DICKSON; ALBAUM, 1977; MANOLIS et al. 1994; KOO, 2003; SINHA; BANERJEE, 2001; COSTA; ALMEIDA, 2008; TELLES et al. 2013).

HIPÓTESE 2: A opinião sobre a aparência física existente no ambiente das lojas do Mercado Ver- o- Peso, encontra-se associada positivamente com a atratividade.

\subsubsection{Preço}

O preço tem papel fundamental na atratividade do local de compra na medida em que alguns atributos aplicados ao processo de formação de preços e a ele diretamente ligados, são importantes e positivamente considerados pelo consumidor, tais como a entrega do produto ou mercadoria, a política de troca e devolução, instalação, pós-venda, serviços de crédito e cobrança e avaliação geral dos serviços (BERRY, 1969; DICKSON; ALBAUM, 1977; DABHOLKAR et al., 1996; BURT; CARRALERO-ENCINAS, 2000; COSTA; ALMEIDA, 2008).

Dentre os atributos acima relacionados e que afetam a atratividade dos locais de venda, a política de crédito e cobrança, segundo Chang e Tu (2005) e Costa e Almeida (2008) é o atributo considerado de maior funcionalidade em relação ao preço, pois é parte fundamental no relacionamento pós-transação ou pós-venda, que se constitui em um dos mais importantes elementos na satisfação do consumidor em relação a um local de venda. Outro elemento considerado na formação de preço e que tem influência na atratividade de uma loja é a política de devolução e troca da compra (BURT e CARRALERO-ENCINAS, 2000; SINHA;

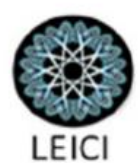


BANERJEE, 2001; COSTA; ALMEIDA, 2008), assim como a política de entrega dos produtos e a garantia a ele associada (BERRY, 1969; JOLSON, 1973; DICKSON; ALBAUM, 1977; BURT0; CARRALERO-ENCINAS, 2000; KOO, 2003; SINHA; BANERJEE, 2001; COSTA; ALMEIDA, 2008).

Outros atributos são também considerados na atratividade das lojas e, segundo expõem Costa e Almeida (2008); Mondo e Costa (2013) podem ser relacionados às promoções de venda, assim, como os benefícios dos custos, prazos e formas de pagamentos.

HIPÓTESE 3: A opinião sobre preço dos produtos ofertados aos consumidores do Mercado Ver-o-Peso, encontra-se associada positivamente com a atratividade.

\subsubsection{Promoção}

Os estudos de Mondo e Costa (2013) pontuam que as promoções de vendas, que possuem elevada influência na atratividade das lojas, são estratégias empresariais destinadas ao esvaziamento de estoques aplicando-se também como estratégia para impulsionar vendas de produtos de baixa saída ou retorno, assim como serve para promover a marca e para a captação de clientes, tratando-se de uma oportunidade para que os clientes avaliem as lojas e os locais de venda (BERRY, 1969; JOLSON; BERRY, 1969; DICKSON; ALBAUM, 1977; BAKER et al. 2002; KOO, 2003; BALTAS; PAPASTATHOPOULOU, 2003; MONDO; COSTA, 2013). HIPÓTESE 4: A opinião sobre promoções de produtos ofertados aos consumidores do Mercado Ver-o-Peso, encontra-se associada positivamente com a atratividade.

\subsubsection{Pessoal e Atendimento}

$\mathrm{O}$ processo de atendimento em venda está diretamente relacionado à atratividade das lojas, em vista da menor ou maior capacidade de interação pessoal do vendedor quanto aos atributos de atenção e cortesia com o consumidor, bem como em razão de sua disponibilidade e conhecimento técnico dos produtos, além da percepção de confiabilidade perante os consumidores (BERRY, 1969; JOLSON;SPATH, 1973; DICKSON;ALBAUM, 1977; MALHOTRA, 1983; DABHOLKAR et al., 1996; BURT; CARRALERO-ENCINAS, 2000; SINHA;BANERJEE, 2001; BAKER et al., 2002; BLOEMER; ODEKERKEN-SCHRÖDER, 2002; KOO, 2003; ORUC, 2005; COSTA; ALMEIDA, 2008).

No mesmo sentido, as ações de atendimento e atenção individualizada influenciam a percepção dos clientes quanto a uma avalição positiva da política de atendimento das lojas varejistas (DABHOLKAR; THORPE; RENTZ, 1996; COSTA; ALMEIDA, 2008).

HIPÓTESE 5: A opinião sobre o atendimento dos vendedores aos consumidores do Mercado Ver-o-Peso, encontra-se associada positivamente com a atratividade.

\subsubsection{Ponto ou Localização e Conveniência}

A localização propicia melhor colocação de produtos e serviços para o cliente, ou seja, a melhor localização física da loja é fator de influência para a determinação de compra dos consumidores que tendem a não escolher lojas distantes de seu ponto de referência, em vista da percepção de conveniência associada à facilidade de acesso ou proximidade, a conveniência proporcionada pela localização de um local de venda é uma variável relevante para a avaliação da atratividade da loja (PARENTE, 2009; BLOEMER e ODEKERKENSCHRÖDER, 2002; KOO, 2003; ORUC, 2005; CHANG e TU, 2005; COSTA; ALMEIDA, 2008; TELLES et al. 2013).

$\mathrm{O}$ atributo de conveniência também está diretamente associado à atratividade na medida em que a loja disponibiliza ao consumidor, produtos e horários diferenciados, permitindo a
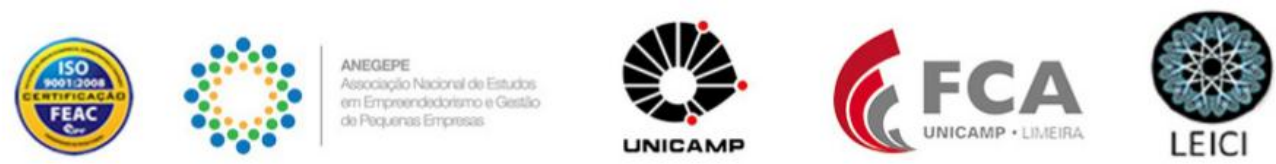
realização de outras atividades às proximidades da loja de venda (KOO, 2003; COSTA; ALMEIDA, 2008).

HIPÓTESE 6: A opinião sobre a localização do Mercado Ver-o-Peso, encontra-se associada positivamente com a atratividade.

\section{ANÁLISE DOS RESULTADOS}

Para verificar se há problemas de multicolinearidade nos dados foi aplicado os testes de Tolerância e de VIF (Variance Inflation Factor). Quando o valor de VIF for maior que 10, isso significa que há problemas de multicolinearidade nos dados. O teste de Tolerância é o inverso do VIF, então, se o valor deste teste for igual a 1 significa que não há multicolinearidade. Na Tabela 1, nenhuma das variáveis apresentam valor de VIF maior que 10 e nenhum valor maior que 1 para o teste de Tolerância, dessa forma, pode-se concluir que não há problemas de multicolinearidade (variáveis altamente correlacionadas) nos dados em estudo.

Tabela 1: Teste de multicolinearidade

\begin{tabular}{clcc}
\hline \multirow{2}{*}{ Model } & & Tolerance & Collinearity Statistics \\
\cline { 2 - 4 } & & 0,238 & VIF \\
\hline \multirow{6}{*}{1} & Produtos & 0,300 & 4,201 \\
& Preços & 0,289 & 3,336 \\
& Lojas & 0,353 & 3,460 \\
& Atendimento & 0,611 & 2,830 \\
& Localização & 0,264 & 1,638 \\
& Condições & & 3,795 \\
\hline
\end{tabular}

Fonte: Resultado da pesquisa, 2017.

Dado os resultados aqui presentes, justifica-se a importância da escolha da regressão logística, uma vez que é menos restritiva ao que tange ao atendimento dessas premissas.

\subsection{Análise da Regressão Logística Multivariada}

A Regressão Logística Múltipla testa uma variável dependente ou variável resposta (Y) e duas ou mais variáveis independentes ou explicativas no modelo, neste caso a variável Y é dicotômica, ou seja, assume apenas dois valores: 0 e 1. Para decidir se o modelo de regressão é adequado, se faz necessário aplicar alguns testes de validação do modelo, como o teste de Hosmer-Lemeshow.

Com base nos 6P's do Mix Varejista, partiu-se para análise de Regressão Logística Múltipla, com a finalidade de verificar quais dos 6P's, impactavam significativamente a atratividade do aglomerado varejista investigado. Logo, tem-se a análise de Regressão Logística multivariada para variável dependente (atratividade) que assume valor 0 ("não atrativo") e 1 ("atrativo") aos consumidores do Mercado do Ver-o-Peso em relação às variáveis independentes (produtos, preços, lojas, atendimento, localização e condições)

\subsubsection{Teste de Significância do Modelo}

O teste de Hosmer \& Lemeshow é um teste de ajustamento de modelo que tem como objetivo avaliar o modelo ajustado, comparando as frequências observadas com as esperadas. Esse teste associa os dados, as suas probabilidades estimadas, dá mais baixa a mais alta, com a utilização do teste Qui-quadrado que determina se as frequências observadas estão próximas das frequências esperadas.

O cálculo demonstra o valor da estatística de Qui-quadrado de 3,385 e p-valor de 0,908. Com esses resultados, pode-se concluir que há evidências estatísticas de que o modelo ajusta-se aos

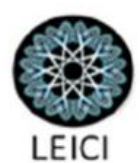


preditos ( $\mathrm{p}>0,05=$ modelo adequado). Estatisticamente pode-se afirmar que os valores previstos dos 6Ps do mix varejista do aglomerado, não são significativamente diferentes dos observados. Isso posto, o modelo aqui proposto, pode ser utilizado para estimar a probabilidade dos consumidores do mercado Ver-o-Peso serem detratores ou promotores. Assim, aceita a hipótese de que não existe diferença entre os valores previstos com os valores que foram observados no construto.

$\mathrm{Na}$ Tabela 2 apresenta o teste do rácio de verossimilhança (Omnibus Tests of Model Coefficients) entre o modelo nulo e os modelos em cada um dos passos (Step), bloco (Block) e modelo final (Model). Para esse teste foi utilizado o método de Enter, ou seja, a inclusão simultânea de todas as variáveis independente explica a coincidência desses valores em que todos os valores são iguais.

Tabela 2: Teste Omnibus Tests of Model Coefficients

\begin{tabular}{lllcc}
\hline & & Chi-square & Df & Significância \\
\hline \multirow{3}{*}{ Step 1 } & Step & 25,663 & 6 & 0,000 \\
\cline { 2 - 5 } & Block & 25,663 & 6 & 0,000 \\
\cline { 2 - 5 } & Model & 25,663 & 6 & 0,000 \\
\hline
\end{tabular}

Fonte: Resultado da pesquisa, 2017

Por meio dos resultados apresentados na Tabela 2, em que o valor da estatística do teste é de 25,663 com p-valor $<0,001$, pode-se concluir que existe pelo menos uma variável independente no modelo com poder preditivo sobre a variável dependente (atratividade). Em relação à estatística de referência, sabe-se que ela é a função de verossimilhança definida como a probabilidade de se obter os resultados da amostra dadas as estimativas dos parâmetros do modelo logístico. Dessa forma, pode-se rejeitar a hipótese de que todos os parâmetros estimados são nulos.

A estatística -2LL que pode ser usada para avaliar a qualidade do ajustamento do modelo. Os resultados dos testes Cox \& Snell e Nagelkerke, obtiveram valores de 0,149 e 0,199 .

A conclusão que se pode chegar com esses indicadores é que eles apontam a proporção das variações ocorridas no log da razão de chance, que por sua vez é explicada pelas variações ocorridas nas variáveis independentes. Dessa forma o Cox \& Snell indica que cerca de 14,9\% das variações ocorridas no log da razão de chance são explicada pelo conjunto das variáveis independentes (produto, preço, lojas, atendimentos, localização e condições de compra). Estatisticamente pode-se considerar que o modelo é capaz de explicar cerca de 19,90\% das variações registradas nas variáveis dependentes, (atrativo e não atrativo).

A Tabela 3 apresenta a classificação dos valores observado e previsto pelo modelo ajustado. Tabela 3: Classification table

\begin{tabular}{|c|c|c|c|c|c|}
\hline \multirow{2}{*}{\multicolumn{2}{|c|}{ Observed }} & & \multicolumn{3}{|l|}{ Predicted } \\
\hline & & & \multicolumn{2}{|c|}{ Situação do Cliente } & \multirow[t]{2}{*}{ Percentage Correct } \\
\hline & & & Não atrativo & Atrativo & \\
\hline \multirow{3}{*}{ Step 1} & Situação do Cliente & Não atrativo & 41 & 33 & 55,4 \\
\hline & & Atrativo & 19 & 66 & 77,6 \\
\hline & Overall Percentage & & & & 67,3 \\
\hline
\end{tabular}

Fonte: Resultado da pesquisa, 2017. 
Hair et al. (2009, p 259) indicam que a fórmula para se chegar a esse cálculo é: $\mathrm{Cpro}=\mathrm{P}^{2}+(1-$ $\mathrm{P})^{2}$. Pode-se observar há 33 indivíduos que consideram como não atrativo o aglomerado varejista, mas que o modelo prediz que consideram como atrativo (falso-positivo) e 19 consideram atrativo e o modelo prediz que não consideram atrativo o aglomerado do Mercado Ver-o-Peso. A sensibilidade do modelo é de $55,4 \%$ e a especificidade é de $77,6 \%$. A porcentagem de casos corretamente classificados é de 67,3\%. Dessa forma pode-se dizer que dos 159 consumidores pesquisados, 74 consideram o Mercado Ver-o-Peso, não atrativo e 85 consideram o mercado atrativo.

\subsubsection{Análise das Hipóteses}

Observa-se que todos os testes sugerem que a técnica estatística pode ser utilizada para estimar a atratividade do consumidor, em relação ao aglomerado do Mercado Ver-o-Peso. Para avaliar o conjunto das variáveis independentes (produtos, preços, lojas, atendimento, localização e condições de compra) que geraram as hipóteses $\mathrm{H}_{1}$ à $\mathrm{H}_{6}$ é preciso avaliar cada coeficiente de regressão do modelo ajustado apresentado na Tabela 4, para posteriormente diagnosticar as hipóteses. Tal tabela exibe as estimativas dos coeficientes logísticos do modelo com seus respectivos desvios padrão, a estatística de Wald, os graus de liberdade, p-valor (nível descritivo), impacto do coeficiente logístico e o intervalo de confiança.

Tabela 4: Modelo logístico

\begin{tabular}{|c|c|c|c|c|c|c|c|c|c|}
\hline & & $\mathbf{B}$ & S.E. & Wald & DF & Sig. & Exp(B) & $\begin{array}{c}95 \% \\
\operatorname{Exp}(\mathbf{B}) \\
\end{array}$ & C.I. for \\
\hline \multirow{8}{*}{$\operatorname{epp} 1^{\mathbf{a}}$} & & & & & & & & Lower & Upper \\
\hline & Produtos & $-0,226$ & 0,223 & 0,014 & 1 & 0,907 & 0,974 & 0,629 & 1,508 \\
\hline & Preços & $-0,084$ & 0,186 & 0,202 & 1 & 0,653 & 0,920 & 0,638 & 1,325 \\
\hline & Lojas & 0,239 & 0,214 & 1,238 & 1 & 0,266 & 1,269 & 0,834 & 1,933 \\
\hline & Atendimento & $-0,166$ & 0,147 & 1,272 & 1 & 0,259 & 0,847 & 0,635 & 1,130 \\
\hline & Localização & 0,441 & 0,128 & 11,876 & 1 & 0,001 & 1,555 & 1,210 & 1,998 \\
\hline & Condições & 0,134 & 0,195 & 0,473 & 1 & 0,492 & 1,143 & 0,780 & 1,675 \\
\hline & Constante & $-2,893$ & 1,004 & 8,301 & 1 & 0,004 & 0,055 & & \\
\hline
\end{tabular}

Fonte: Resultado da pesquisa, 2017.

A estimativa do coeficiente logístico das variáveis lojas, localização e condições, apresentam sinal positivo. Portanto, indica uma maior probabilidade de atrair os consumidores ao cluster varejista Mercado Ver-o-Peso. Em contrapartida às variáveis produtos, preços e atendimento, apresentaram coeficientes negativos, indicando que existem variáveis positivas dessas variáveis, que estão contribuindo para reduzirem a probabilidade de atrair consumidores ao Mercado do Ver-o-Peso.

A estatística de Wald é definida como o quadrado da razão entre o coeficiente logístico estimado e o seu erro padrão. Tomando como base o modelo estatístico que apresenta distribuição Quiquadrado, coloca-se a teste a seguinte hipótese estatística para cada variável independente.

\section{H0: o coeficiente logístico é igual à zero.}

De acordo com o resultado do p-valor mostrado na Tabela 4 e considerando o nível de significância de 5\%, destaca-se que os coeficientes das variáveis incluídas no modelo logístico não são estatisticamente diferentes de zero; isso posto, no que tange às variáveis produtos, preços, lojas, atendimento e condições, não apresentam poder de discriminação; e que, somente a variável localização, incluída no modelo, foi estatisticamente significativa, apresentando o maior valor da estatística de Wald (11,876). Dessa forma, das hipóteses H1 a H6 testadas, somente a variável localização apresenta nível de significância inferior a 0,05 , aceitando a seguinte hipótese:

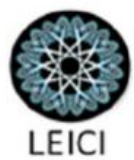


Hipótese 5: A opinião sobre a localização do aglomerado varejista Mercado Ver-o-Peso, está associada positivamente com a atratividade.

Diante disso, as variáveis produtos, preços, lojas, atendimento e condições de compra foram rejeitadas, por apresentarem níveis de significância superior a 0,05 , conforme se apresentam na Tabela 6. Assim, pode-se afirmar que somente a localização é o fator de atratividade do Mercado Ver-o-Peso, na opinião dos frequentadores desse cluster.

\section{CONCLUSÃO}

A atratividade de consumidores por parte de unidades varejistas tem sido estudada, e apresenta uma abordagem já bem consolidada na literatura. No entanto, ao que se refere à atratividade de aglomerados varejistas e que aborda a ótica do consumidor, é uma questão relativamente recente. Assim, acredita-se que os resultados apresentados nesta pesquisa, podem contribuir positivamente para a literatura do marketing varejista, mediante evidências empíricas apontadas neste estudo. A abordagem original sobre atratividade de um aglomerado de lojas varejistas, com característica preponderante de micro e pequenas empresas é uma das contribuições desse estudo.

O estudo apresenta que a localização do cluster Mercado Ver-o-Peso, foi aceita e possui associação positiva e direta com a atratividade sob a percepção dos consumidores que estavam no referido cluster fazendo suas compras. Vale lembrar, que a indicação da variável localização é muito discutida na literatura, e encontra-se já consolidada como um fator de atratividade dos locais de vendas e lojas, na opinião dos consumidores.

Assim, pode-se inferir que a variável localização, apontada nesse estudo como fator que atrai os consumidores a comprar no Mercado Ver-o-Peso pode não estar associada somente as belezas naturais que circunvizinham o mercado (Rio Guamá - Baia do Guajará), e sim, a facilidade da localização para a acessibilidade do consumidor, via de regra por transportes terrestres coletivo que são ofertados em grandes variedades. $O$ fato do mercado estar situado no centro da capital paraense contribui para essa vantagem. Pode atribuir também, a oferta dos estacionamentos particulares a um preço de R \$3,00 (Três Reais) por hora. Outra opção de acesso ao mercado é por via fluvial, porém em menor escala que a terrestre.

Estudo realizado por Costa e Almeida (2008) e Teller et al. (2013), indicam que a conveniência de localização como a possibilidade de realizar todas as compras em um só local é um dos fatores que atraem os consumidores para os aglomerados. Essa facilidade de encontrar tudo em um só local é percebido no Mercado Ver-o-Peso, pois o consumidor vai comprar o peixe e também leva a farinha, as verduras e frutas fresquinhas, o açaí que é um alimento típico e muito consumido pela maioria dos paraenses.

Em nível inferior à localização, as variáveis independentes lojas e condições de compra também apresentaram sinal positivo de associação com a atratividade do consumidor, o que não ocorreu com as variáveis produtos, preços e atendimento, as quais apresentaram estimativas do coeficiente negativo, o que indica uma menor probabilidade de atrair consumidores ao Mercado.

Quanto ao preço, embora esteja relacionado aos serviços prestados aos clientes, tais como: serviços de crédito e cobrança, entrega, instalação, pós venda, bem estruturada, política de troca de mercadorias etc. Esses serviços não existem no Mercado Ver-o-Peso. Em relação a quantidade de produtos ofertados, a literatura diz que, quando o consumidor tem a certeza de

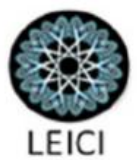


encontrar determinado produto com vários modelos e marcas e com qualidade, esses quesitos influenciam a atratividade do local.

O Mercado Ver-o-Peso, apresenta uma grande quantidade e variedade de produtos, mas, não o suficiente para tornar essa variável um fator que atrai os consumidores ao aglomerado varejista. $\mathrm{O}$ atendimento, ligado ao fator interação pessoal, ou seja, os elementos relativos a atenção, cortesia, simpatia dos vendedores confiabilidade do pessoal que interagem com os consumidores no varejo, conforme destacado por Baker et al.(2002); Bloemer e OderkenSchroder (2002) Koo (2003) também não foram considerados como atrativos. Outra variável aqui estudada, diz respeito às Lojas, seu estilo, a aparência externa, mobiliário de exposição, ambiente da loja, modalidade das instalações, limpeza, arrumação, decoração, são fatores considerados atrativos por Koo (2003); Sinha e Benerjee (2004); Costa e Almeida (2008) e Telles et al. (2013). Na opinião dos consumidores pesquisados no Mercado Ver-o-Peso, tais características não foram consideradas atrativas.

Por último, as condições de compras que são influenciadas pelas promoções das lojas e locais e pelas formas de pagamentos diferenciadas, não foram consideradas atrativas, uma vez que, no Mercado Ver-o-Peso só existe uma única forma de pagamento que é em espécie ou seja, dinheiro, desse modo os micros empresários ainda não aderiram a modernidade das máquinas de cartão de crédito. Assim, dentro do mix varejista estudado nesse artigo, onde se destaca. Produtos, Preços, Lojas, Atendimentos, Localização e Condições, somente a variável localização foi considerada atrativa para os 159 consumidores que foram entrevistados no Mercado Ver-o-Peso.

Como limitação desse estudo, pode-se destacar a utilização de amostra não probabilística por conveniência e ao fato de que não permite a generalização dos resultados, por esse estudo obtido, pois o cluster regional alvo da pesquisa é extremamente específico.

\section{REFERENCIAS}

AGUIAR, H. S.; PEREIRA, C. E. C.; DONAIRE, D. Polo varejista do bom retiro: cluster de negócios da moda. In: SIMPOI - Simpósio de Administração da Produção, Logística e Operações Internacionais. XVII, 2014. São Paulo. Anais... São Paulo, FGV 2014.

AMATO NETO, J. Gestão de Sistemas Locais de Produção e Inovação (Clustes/APLs), 1. ed., São Paulo: Atlas, 2009.

ARENTZE, T. A.; OPPEWAL, H.; TIMMERMANS, H. J. P. A multipurpose shopping trip model to assess retail agglomeration effects. Journal of Marketing Research, v. XLII, February 2005.

BAKER, J.; PARASURAMAN, A.; GREWAL, D.; VOSS, G. B. The influence of multiple store environment cues on perceived merchandise value and patronage intentions. Journal of Marketing, v. 66, n. 2, p. 120-141, 2002.

BALTAS, G.; PAPASTATHOPOULOU, P. Shopper characteristics, product and store choice criteria: a survey in the greek grocery sector. International Journal of Retail and Distribution Management, v. 31, n. 10, p. 498-507, 2003.

BELÉM. Secretaria Municipal de Economia - SECON. www.belem.pa.gov.br/secon/sitel. Aceso em 07 de fev. 2017.

BENKO, G. Economia, espaço e globalização: na aurora do século XXI. $2^{\mathrm{a}}$ ed. São Paulo: Atlas, 2000.

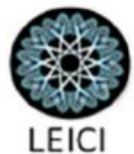


BERRY, L. L. The components of department store image: a theoretical and empirical analysis. Journal of Retailing, v. 45, n. 1, p. 3-20,1969.

BLOEMER, J.; ODEKERKEN-SCHRÖDER, G. Store satisfaction and store loyalty explained by customer - and store-related factors. Journal of Consumer Satisfaction, Dissatisfaction and Complaining Behavior, v. 15, p. 68-80, 2002.

BRITO, E. P.Z. et al. A relação entre aglomeração produtiva e crescimento: a aplicação de um modelo multinível ao setor industrial paulista. Revista de Administração Contemporânea, v.14, n.4, p. 615-632, ago. 2010.

BURT, S.; CARRALERO-ENCINAS, J. The role of store image in retail internationalization. International Marketing Review, v. 17, n. 4/5, p. 433-453, 2000.

CARVALHO, V.B de; MENDONÇA, G.C.; STEINBRENNER, R. De mãe para filha: o desafio de comunicar o saber tradicional na Amazônia. In...II Conferência Sul-Americana e VII Conferência Brasileira de Mídia Cidadã, 17 a 22 de outubro de 2011, Belém (PA), Brasil.

CASAROTTO FILHO, N.; PIRES, L.H. Redes de pequenas e médias empresas e desenvolvimento local. $2^{a}$ ed., São Paulo: Prentice Hall, 2002.

CHANG, C.; TU, C. Exploring store image, customer satisfaction and customer loyalty relationship: evidence form taiwanese hypermarket industry. Journal of American Academy of Business, v. 7, n. 2, p. 197-202, 2005.

COSTA, L. S.; ALMEIDA, V. M. C.; Imagem dos locais de venda de bens de consumo: proposição e teste empírico de um modelo dos fatores formadores da imagem na perspectiva do consumidor. In: EMA - Encontro de Marketing do Encontro da Associação Nacional de Pós-Graduação e Pesquisa em Administração, III, Curitiba, 2008. Anais... Rio de Janeiro: ANPAD, 2008, p. 1-16.

DABHOLKAR, P. A.; THORPE, D. I.; RENTZ, J. O. A measure of service quality for retail stores: scale development and validation. Journal of the Academy of Marketing Science, v. 24, n. 1, p. 3-16, 1996.

DE WULF, P. V. K. K.; WATERSCHOOT, W. V. The impact of task definition on storeattribute saliences and store choice. Journal of Retailing, v. 75, n. 1, p. 125-137, 1999.

DICKSON, J.; ALBAUM, G. A method for developing tailormade semantic differentials for specific marketing content areas, Journal of Marketing Research, v. 14, feb, p. 87-91, 1977. FENSTERSEIFER, J.E.; WILK, E.O. Visão da firma baseada em recursos, clusters e performance: um estudo no setor vitivinícola do RS. In.... XXIX ANPAD. Brasília, 2005.

GASPAR, M. A.; SILVA, R. S.; ZUCHINI, V. D.; RENZO, G.; MURARI, J. M. Vantagens Competitivas de um Cluster Comercial Varejista: Estudo de Caso da Rua Jurubatuba. Revista Sinergia. V. 19 n.1 pp.9-20, 2015.

GASPAR, M. A.; SILVA, R. S.; ZUCHINI, V. D.; RENZO, G.; MURARI, J. M. Vantagens Competitivas de um Cluster Comercial Varejista: Estudo de Caso da Rua Jurubatuba. Revista Sinergia. V.19 n.1 pp.9-20, 2015.

HAIR, J. F.; ANDERSON, Rolph E.; TATHAM, Ronald L.; BLACK, William C. Análise multivariada de dados. Porto Alegre: Bookman, 2005. Tradução da $5^{\mathrm{a}}$ edição americana por Adonai Schlup Sant Anna e Anselmo Chaves Neto.

INGENE, C. A. Productivity and functional shifting in spatial retailing: private and social perspectives. Journal of Retailing and Consumer Services, v. 60, n. 3, p. 15-26, 1984 
JOLSON, M. A.; SPATH, W. F. Understanding and fulfilling shoppers' requirements: ananomaly in retailing. Journal of Retailing, v. 49, n. 2, p. 38-50, 1973.

KOO, D. Inter-relationships among store images, store satisfaction, and store loyalty among Korea discount retail patrons. Asia Pacific Journal of Marketing and Logistics, v. 15, n. 4, p. 42-71, 2003.

LEITÃO, W. M. Ver-o-Peso: um mercado de coisas boas e belas. In... IV Colóquio Internacional sobre o comércio e cidade, Uberlândia, 2013.

MALHOTRA, N. K. A threshold model of store choice. Journal of Retailing, v. 59, n. 2, p. 3-21, 1983.

MANOLIS, C.; KEEP, W. W.; JOYCE, M. L.; LAMBERT, D. R. Testing the underlying structure of a store image scale. Educational and Psychological Measurement, v. 54, p. 628645, 1994.

MARTINEAU, P. The personality of retail store. Harvard Business Review, v. 33, p. 47-55, 1958.

MARSHALL, Alfred. Princípios de economia. São Paulo: Nova Cultural, 1988.

MILANEZ, B; PUPPIM, J. A. Ambiente, pessoas e labor: APLs além do desenvolvimento econômico na mineração de opalas em Pedro II, no Piauí. Cad. EBAPE.BR, v. 7, n. 4, p. 527 546, dez. 2009.

MONDO, T. S.; COSTA, J. I. P. A Influência da promoção de vendas na captação de clientes: Um estudo na hotelaria catarinense. Revista Brasileira de Marketing - REMark, v. 12, n. 2, p. 87-107, 2013.

ORUC, N. Retail gravity model analysis of store choice behaviour of hypermarket shoppers in Sarajevo. European Retail Digest, v. 47, p. 31-34, 2005.

PARENTE, J. Varejo no Brasil: gestão e estratégia. São Paulo: Atlas, 2009.

PORTER, M. E. Competitive advantage. New York: The Free Press, 1985.

The competitive advantage of nations. New York: The Free Press, 1990.

PERRY, M. Business Cluster: an international perspective. New York, USA: Routledge, 2005. ROGERS, A. A stochastic analysis of the spatial clustering of retail establishments. Journal of the American Statistical Association, n. 312: 1094. v. 60, Dec 1965.

SILVA, R. S.; DONAIRES, D.; GASPAR, M. A.; ARAÚJO M. F. Fatores Formadores de Atratividade na Perspectiva do Consumidor Brasileiro na Aglomeração Varejista da Fronteira Brasil/Venezuela. In: VI Encontro de Marketing da ANPAD. Anais... Gramado - RS, Porto Alegre, 2014.

SILVA, R. S. Coopetição em aglomerações comerciais planejadas e não planejadas. $226 \mathrm{f}$ Tese (Doutorado em Administração) pela Universidade Municipal de São Caetano do Sul. São Caetano do Sul, 2016.

SILVA, R. S.; DONAIRES, D.; GASPAR, M. A.; ARAÚJO M. F. Fatores Formadores de Atratividade na Perspectiva do Consumidor Brasileiro na Aglomeração Varejista da Fronteira Brasil/Venezuela. In: VI Encontro de Marketing da ANPAD. Anais... Gramado - RS, Porto Alegre, 2014.

SINHA, P. K.; BANERJEE, A. Store choice behaviour in an evolving market. International Journal of Retail and Distribution Management, v. 32, n. 10, p. 482-494, 2001.
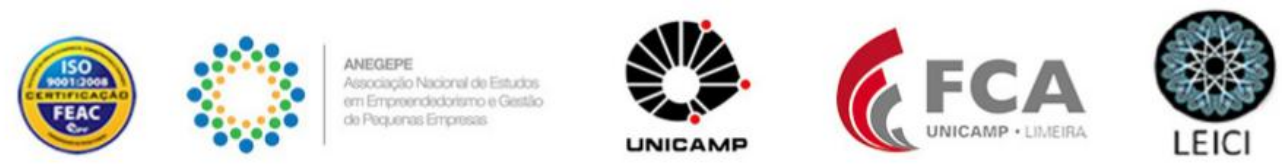
SIQUEIRA, J. P. L.; TELLES, R.; ROCCA, M. E.; GASPAR, M. A. Clusters Varejistas: Características Responsáveis pela Atração e Afastamento de Consumidores, E\&G Economia e Gestão, Belo Horizonte, v. 15, n. 38, 2015.

SCHMITZ, H. On the clustering of small firms. IDS Bul- letin, v.23, n.3, pp.540-559, 1992.

SIQUEIRA, J. P. DE L; GERTH, F. M.; BOAVENTURA, J. M. G. Análise de Clusters Industriais de Calçados de Franca e Birigui. Revista Gestão Organizacional, v.4 n.2 pp.198216, 2011.

SIQUEIRA, J. P. L.; TELLES, R. Atributos e Imagem dos Clusters de Negócios Varejistas. Revista Gestão \& Tecnologia, Pedro Leopoldo, v. 15, n. 2, p. 29-49, 2015.

SOUZA, S. D.C.; ARICA, J. Mudança tecnológica e estratificação competitiva em um arranjo produtivo do setor ceramista. Revista Produção, v. 16, n. 1, p. 88-99, 2006.

SOUZA. R. V. Os Canais de Distribuição como parte do Composto de Marketing adotado na Comercialização de Produtos Evangélicos: fatores de sucesso da Rua Conde de Sarzedas. 134 f Dissertação (Mestrado em Administração). Universidade Municipal de São Caetano do Sul-SP, São Paulo, 2013.

SOUSA, F. G. P.; SOUZA, L. L. F.; PEÑALOZA, V.; FERREIRA, M. A. B. Comportamento de Compra no Pequeno Varejo: Consumo Hedônico e Utilitário. Revista Ciência Admin. Fortaleza, v. 20, n. 1, p. 285-312, 2014.

TELLER, C. Shopping streets versus shopping malls: determinants of agglomeration format attractiveness from the consumer's point of view. International Review of Retail, Distribution \& Consumer Research, v. 18, n. 4, p. 381-403, 2008.

TELLES, R.; SIQUEIRA, J. P. L.; DONAIRE, D.; GASPAR, M. A.; Atratividade em clusters comerciais: um estudo comparativo de dois clusters da cidade de São Paulo. Gestão e Regionalidade, v. 29, n. 85, p. 47-62, 2013.

ZACCARELLI, S. B.; TELLES, R.; SIQUEIRA, J. P. L.; BOAVENTURA, J. M. G.; DONAIRE, D. Clusters e redes de negócios: uma nova visão para a gestão dos negócios. São Paulo: Atlas, 2008. 